\title{
Risk of fentanyl-involved overdose among those with past year incarceration: Findings from a recent outbreak in 2014 and 2015
}

\author{
Lauren Brinkley-Rubinstein $^{\mathrm{a}, \mathrm{b}, *}$, Alexandria Macmadu ${ }^{\mathrm{c}, \mathrm{d}}$, Brandon D.L. Marshall ${ }^{\mathrm{e}}$, Andrew Heise ${ }^{\mathrm{b}}$, \\ Shabbar I. Ranapurwala ${ }^{\mathrm{f}}$, Josiah D. Rich ${ }^{\mathrm{c}, \mathrm{e}}$, Traci C. Green ${ }^{\mathrm{g}, \mathrm{h}}$ \\ a Department of Social Medicine, University of North Carolina, 333 S. Columbia St., Chapel Hill, NC 27516, USA \\ ${ }^{\mathbf{b}}$ Center for Health Equity Research, University of North Carolina at Chapel Hill, 335 S. Columbia St., Chapel Hill, NC 27516, USA \\ ${ }^{c}$ Center for Prisoner Health and Human Rights, The Miriam Hospital, 8 Third St., 2nd floor, Providence, RI 02906, USA \\ ${ }^{\mathrm{d}}$ Department of Health Services, Policy and Practice, Brown University School of Public Health, 121 South Main St., Providence, RI 02903, USA \\ e Department of Epidemiology, Brown University School of Public Health, 121 South Main St., Providence, RI 02903, USA \\ ${ }^{\mathrm{f}}$ Department of Epidemiology, University of North Carolina, 135 Dauer Dr., Chapel Hill, NC 27599, USA \\ ${ }^{g}$ Department of Emergency Medicine, Boston University, 1 Boston Medical Center Pl, Boston, MA 02118, USA \\ h Injury Prevention Research Center, Boston University, 1 Boston Medical Center Pl., Boston, MA 02118, USA
}

\section{A R T I C L E I N F O}

Keywords:

Incarceration

Fentanyl

Overdose

\begin{abstract}
A B S T R A C T
Overdose is the leading cause of unintentional injury-related death. Rhode Island (RI) has the highest rate of illicit drug use nationally and the 5th highest overdose mortality rate. RI has experienced an outbreak of fentanyl-related overdoses. In incarcerated populations, risk of overdose is greatly elevated. However, little is known about fentanyl-related overdose post-release. In the current analyses, we identify changes in fentanylrelated fatal overdose among those who died in 2014 and 2015 who were incarcerated in the year before death. We linked data from the RI Office of the Medical Examiner with records from the RI Department of Corrections. We calculated risk ratios and $95 \%$ confidence intervals using log-binomial regression to compare risk of fentanylinvolved overdose death. We also compared median time to death since release, median sentence length, and median number of incarcerations in 2014 and 2015. Results indicate that the risk of dying of a fentanyl-related overdose increased (RR: 1.99 (95\% CI: 1.11-3.57, p = 0.014)) from 2014 to 2015 among those with past year incarceration. This study is one of the first to describe fentanyl-related fatal overdose among those with past year incarceration. In 2015 the median sentence was longer among those with a fentanyl-related overdose death and the median time from release to death among all who had past year incarceration extended past 90 days. Access to medications for addiction treatment, overdose education, and naloxone should be available during community re-entry and extended beyond the early post-release period.
\end{abstract}

\section{Introduction}

Overdose is the leading cause of unintentional, injury-related death in the United States (Warner et al., 2009). Rhode Island (RI) has the highest rate of illicit drug use nationally and the 5th highest overdose mortality rate (Rudd, 2016; Substance Abuse and Mental Health Services Administration, 2014). Like other states, RI is experiencing a dramatic rise in overdose deaths with an increase of more than $90 \%$ from 2011 to 2016 (Rhode Island Department of Health, 2016). Across the US, increasing overdose deaths have been accompanied by an outbreak of fentanyl-contaminated heroin and other drugs. Fentanyl is a synthetic opioid that is 50-100 times stronger than most other opioids (O’Donnell et al., 2017; Drug Enforcement Administration, 2017). From
2013 to 2015, overdose deaths that involved synthetic opioids and heroin increased more sharply than deaths that only included heroin in the Southern, Midwestern, and Northeastern US (O'Donnell et al., 2017). The number of fentanyl-involved overdose deaths in RI increased 15-fold from 2009 to 2016 (Rhode Island Department of Health, 2016). In 2014, 35\% of all overdose deaths involved fentanyl, increasing to 50\% in 2016 (Marshall et al., 2017).

In criminal justice (CJ)-involved populations, the risk of overdose is greatly elevated (Binswanger et al., 2016; Merrall et al., 2010). Nearly a third of all individuals who are addicted to heroin pass through the CJ system in any given year, and a majority of those incarcerated in local jails report issues with substance use (James and Glaze, 2006). Over $23 \%$ of state prisoners report ever using heroin or other opiates, and

\footnotetext{
* Corresponding author at: Department of Social Medicine, University of North Carolina, Chapel Hill, 333 S. Columbia St., Chapel Hill, NC, 27559, USA.

E-mail address: Lauren_Brinkley@med.unc.edu (L. Brinkley-Rubinstein).
} 
13\% report regular use before incarceration (Mumola and Karberg, 2006). Among those incarcerated at the Rhode Island Department of Corrections (RIDOC), 18.5\% meet the criteria for opioid use disorder; in fiscal year 2015, about $12 \%$ of all people at the RIDOC were incarcerated due to a drug charge (Rhode Island Department of Corrections, 2015).

The time immediately after release from jail or prison is a period of extreme risk of fatal overdose. In Washington State, overdose death was the leading cause of death among those who were recently incarcerated (Binswanger et al., 2016). However, very little is known about fentanylrelated overdose deaths post-release. In the current analyses, we identify changes in fentanyl-related fatal overdose among those with recent incarceration from 2014 to 2015.

\section{Methods}

We linked data from the RI Office of the Medical Examiner on overdose deaths (occurring January 1, 2014, to December 31, 2015) with records from the RIDOC. Data were linked deterministically by name and date of birth. We calculated risk ratios (RR) and 95\% confidence intervals (CI) using log-binomial regression to compare risk of fentanyl-involved overdose death among those who died in 2014 and 2015 and were incarcerated in the year prior to their death. During the study period, there were a total of 530 fatal overdoses, and 79 were among those who had past year incarceration. We also compared median time to death since release, median sentence length, and median number of incarcerations in 2014 and 2015.

\section{Results}

Among those with past year incarceration $(\mathrm{n}=79), 35$ overdose deaths (44\%) involved fentanyl (see Table 1). The majority of decedents with past year incarceration were white, male, and aged 18-39. From 2014 to 2015, the total number of overdose deaths in RI increased; there were 240 overdose deaths in 2014 and 290 in 2015. The number of overdose deaths among those with past year incarceration remained relatively steady over the study period, with 35 (14.6\%) overdose deaths in 2014 and 44 (15.2\%) in 2015 .

Among all overdose decedents, the number of fentanyl-involved overdose deaths increased each year as well, with 84 (35\%) fentanylinvolved overdose deaths in 2014 and 136 (47\%) in 2015. Among those with past year incarceration, the proportion of fentanyl-involved overdose deaths increased significantly from 2014 to 2015 (from 29\% to $56 \%, p=0.02$ ). The RR for fentanyl-related overdose death among those with past year incarceration in 2015 compared to 2014 was 1.99 (95\% CI: $1.11-3.57, p=0.014$ ).

Among those with past year incarceration, for those whose overdose death did not involve fentanyl, the median length of sentence decreased from 50 days in 2014-15 days in 2015 ( $p=0.1572)$. However, among those whose overdose death involved fentanyl, the median length of sentence increased from 21 days in 2014-58 days in $2015(p=0.4342)$. The median number of past year incarcerations at the RIDOC and the number of decedents with 30 or fewer days between release and death remained steady during the study period for all those with past year incarceration. However, the median days from release to death for both non-fentanyl-related (99 days to 103 days; $p=0.8344$ ) and only fentanyl-related ( 40 days to 135 days, $p=0.2735$ ) deaths among those with past year incarceration increased from 2014 to 2015. While these changes were not significant, it is worth noting that, for 2015, in all overdose deaths among those with past year incarceration the median time from release to death was over 90 days.

\section{Discussion}

This is one of only a few recent studies that have described past year incarceration among people who died of overdose and is the first report of fentanyl-involved overdose among those with recent incarceration during the current fentanyl crisis (Marshall et al., 2017; Merrall et al., 2010). Findings suggest that, compared to 2014, 2015 is marked by a higher risk of fentanyl-involved deaths for those with past year incarceration. Identifying the mechanisms driving the increase in fentanyl-related deaths among those with recent incarceration requires further investigation, but uncovering the ways that incarceration impacts people during community re-entry is warranted. For instance, incarceration may lower knowledge of the drug supply's quality and possible contamination. During incarceration, people are removed from their communities and often abstain from drug use. Therefore, when people are released from jail or prison, they may be unfamiliar with the presence of fentanyl contaminates in other opioids. In addition, incarceration may interrupt people's regular supply chain. People who use opioids have reported that maintaining long-term relationships with dealers, whom they trust to test their products prior to sale, is one strategy to guard against unwanted fentanyl adulteration (Carroll et al., 2017). These relationships are disrupted when dealers or users are arrested. Finally, law enforcement-driven responses to the fentanyl overdose epidemic might also increase the likelihood of incarceration

Table 1

Sociodemographic characteristics of individuals who had a fatal overdose, 2014-2015.

\begin{tabular}{|c|c|c|c|c|c|c|c|c|c|c|c|c|c|c|c|}
\hline & \multicolumn{7}{|c|}{ Recent incarceration $(n=79)$} & \multicolumn{7}{|c|}{ No incarceration $(n=451)$} & \multirow{3}{*}{$\begin{array}{l}\text { Recent vs. no } \\
\text { incarceration } \\
\text { p-value }\end{array}$} \\
\hline & \multicolumn{2}{|c|}{ Total $(n=79)$} & \multicolumn{2}{|c|}{$2015(n=44)$} & \multicolumn{2}{|c|}{$2014(n=35)$} & \multirow{2}{*}{$\begin{array}{l}2015 \mathrm{v} . \\
2014 \\
p \text {-value }\end{array}$} & \multicolumn{2}{|c|}{ Total $(n=451)$} & \multicolumn{2}{|c|}{$2015(n=246)$} & \multicolumn{2}{|c|}{$2014(n=205)$} & \multirow{2}{*}{$\begin{array}{l}2015 \mathrm{v} . \\
2014 \\
p \text {-value }\end{array}$} & \\
\hline & $n$ & $\%$ & $n$ & $\%$ & $n$ & $\%$ & & $n$ & $\%$ & $n$ & $\%$ & $n$ & $\%$ & & \\
\hline \multicolumn{16}{|l|}{ Race } \\
\hline White & 71 & 89.9 & 42 & 95.5 & 29 & 82.9 & & 407 & 90.2 & 224 & 91.1 & 183 & 89.3 & & \\
\hline Non-white & 8 & 10.1 & 2 & 4.6 & 6 & 17.1 & 0.165 & 44 & 9.8 & 22 & 8.9 & 22 & 10.7 & 0.542 & 0.918 \\
\hline \multicolumn{16}{|l|}{ Age } \\
\hline $18-29$ & 28 & 35.4 & 15 & 34.1 & 13 & 37.1 & 0.780 & 85 & 18.8 & 55 & 22.4 & 30 & 14.6 & $0.023^{*}$ & $0.000^{*}$ \\
\hline $30-39$ & 23 & 29.1 & 12 & 27.3 & 11 & 31.4 & 0.693 & 104 & 23.1 & 52 & 21.1 & 52 & 25.4 & 0.306 & 0.241 \\
\hline $40-49$ & 18 & 22.8 & 11 & 25.0 & 7 & 20.0 & 0.583 & 104 & 23.1 & 48 & 19.5 & 56 & 27.3 & 0.067 & 0.957 \\
\hline $50+$ & 10 & 12.7 & 6 & 13.6 & 4 & 11.4 & 0.760 & 158 & 35.0 & 91 & 37.0 & 67 & 32.7 & 0.333 & $0.000^{*}$ \\
\hline \multicolumn{16}{|l|}{ Gender } \\
\hline Male & 64 & 81.0 & 34 & 77.3 & 30 & 85.7 & & 312 & 69.2 & 174 & 70.7 & 138 & 67.3 & & \\
\hline Female & 15 & 19.0 & 10 & 22.7 & 5 & 14.3 & 0.296 & 139 & 30.8 & 72 & 29.3 & 67 & 32.7 & 0.442 & $0.039^{*}$ \\
\hline Fentanyl & 35 & 44.3 & 25 & 56.8 & 10 & 28.6 & $0.013^{*}$ & 185 & 41.0 & 111 & 45.1 & 74 & 36.1 & $0.049^{*}$ & 0.584 \\
\hline
\end{tabular}

Note: for chi-square tests, referent level for race is "white", reference value for gender is "male".

$* p<0.05$. 
for drug users and may also explain the increase in median sentence length for those with a fentanyl-related overdose in 2015.

The increase in fentanyl-related deaths among those with past year incarceration from 2014 to 2015 also demonstrates the need for evidencebased overdose education and interventions, especially the provision of naloxone at release and treatment with medications for addiction treatment. The results of this study provide a strong rationale to prioritize training and the provision of the antidote naloxone to individuals leaving correctional custody in both jails and prisons, regardless of sentence length. Exemplar programs that could be adapted in jail or prison settings include the DOPE Project in California and the Harm Reduction Coalition's work in the New York state prison system, both of which have developed overdose training modules and naloxone provision strategies (see: http:// harmreduction.org/issues/overdose-prevention/tools-best-practices/ naloxone-program-case-studies/dope-project/and http://harmreduction. org/miscellaneous/overdose-prevention-nyc-prison/).

Most previous research has demonstrated that the early post-release period (anywhere from the first two weeks to the first 90 days) is the time when recently incarcerated individuals are at the highest risk of overdose (Binswanger et al., 2007; Spaulding et al., 2011; Zlodre and Fazel, 2012). However, our findings indicate that people may be experiencing fatal overdoses for a more extended period during community re-entry, underscoring the importance of continued access to medications for addiction treatment and naloxone many months after release. The longer median time from release to death may be explained by an increase in the number of overdose-related interventions that have been rapidly implemented in RI, translating into an uptick in services available for individuals immediately after release (Montanaro et al., 2015).

Finally, it is worth noting that this study was made possible because we were able to match RIDOC data with records from the RI Office of the Medical Examiner. Other jurisdictions should similarly link administrative datasets to obtain a more comprehensive understanding of their local overdose epidemic. Several states and cities such as RI, Maryland, and New York City have published reports that can help guide this process (Marshall et al., 2017; Cherisco-Hsii et al., 2014; Heller et al., 2014)

\section{Conclusion}

This study is one of the first to describe fentanyl-related fatal overdose among those with past year incarceration. Results indicate that, while the proportion of past year incarceration among those who died of an overdose in 2014 and 2015 remained steady, the risk of dying of a fentanyl-related overdose increased. These findings underscore the importance of comprehensive access to medications for addiction treatment and naloxone during the extended community reentry period.

\section{Role of funding}

Funding for this study was provided by The Brown Initiative in HIV and AIDS Clinical Research for Minority Communities, R25MH083620, The UCLA HIV/AIDS, Substance Abuse and Trauma Training Program (HA-STTP), The HIV and Other Infectious Consequences of Substance Abuse, T32DA013911, and The Lifespan/Brown Criminal Justice Research Program on HIV and Substance Use, R25DA037190.

\section{Contributors}

All authors made significant contributions to the study's design and conduct. LBR was the lead author and prepared initial drafts of this report. AM and LBR conducted study analyses. AM, BDLM, AH, SIR, JDR, and TCG critiqued the analysis plan, assisted with the interpretation of findings, and contributed to multiple versions of this brief. All authors contributed to and have approved the final manuscript for publication.

\section{Conflict of interest}

All authors declare that they have no conflicts of interest.

\section{Acknowledgements}

This work is supported by NIH grant R21DA029201. The work of Drs. Green and Rich are also supported by NIH grants K24DA022112 and P30AI042853(JDR) and CDC grant R21CE001846 (TCG). Dr. Marshall is supported by the National Institute on Drug Abuse (DP2DA040236). Dr. Brinkley-Rubinstein is supported by the UCLA HIV/AIDS, Substance Abuse and Trauma Training Program (HA-STTP) (R25DA035692), the HIV and Other Infectious Consequences of Substance Abuse Training ProgramT32DA013911), and the Lifespan/ Brown Criminal Justice Research Program on HIV and Substance Use (R25DA037190). The funders had no role in the design, analysis, interpretation, writing, review, preparation, or decision to publish this manuscript.

\section{References}

Binswanger, I.A., Stern, M.F., Deyo, R.A., Heagerty, P.J., Cheadle, A., Elmore, J.G., Koepsell, T.D., 2007. Release from prison - a high risk of death for former inmates. N. Engl. J. Med. 157-165 2007.

Binswanger, I.A., Stern, M.F., Yamashita, T.E., Mueller, S.R., Baggett, T.P., Blatchford, P.J. 2016. Clinical risk factors for death after release from prison in Washington State: a nested case-control study. Addiction 111, 499-510.

Carroll, J.J., Marshall, B.D., Rich, J.D., Green, T.C., 2017. Exposure to fentanyl-contaminated heroin and overdose risk among illicit opioid users in Rhode Island: a mixed methods study. Int. J. Drug Policy 46, 136-145.

Cherisco-Hsii, S., Bankoski, A., Singal, P., Horon, I., Beane, E., Casey, M., Robbert-Franklin, K., Sharfstein, J., 2014. Sharing overdose data across state agencies to inform public health strategies: a case study. Public Health Rep. 131, 258-263.

Drug Enforcement Administration,, 2017. National Drug Threat Assessment Summary. US Department of Justice, Drug Enforcement Administration 2017, Washington, DC

Heller, D., Bradley O'Brien, D., Harocopos, A., Hreno, J., Lerner, J., McCoy, E.B., Nolan, M., Phillips Lum, P., Tuazon, E., Parker, C., Kunins, H., Paone, D., 2014. RxStat: Technical Assistance Manual. New York City.

James, D.J., Glaze, L.E., 2006. Mental health problems of prison and jail inmates. Bureau of Justice Statistics Special Report.

Marshall, B.D., Krieger, M.S., Yedinak, J.L., Ogera, P., Banerjee, P., Alexander-Scott, N.E., Rich, J.D., Green, T.C., 2017a. Epidemiology of fentanyl-involved drug overdose deaths: a geospatial retrospective study in Rhode Island, USA. Int. J. Drug Policy 46, 130-135.

Marshall, B.D.L., Yedinak, J.L., Goyer, J., Green, T.C., Koziol, J.A., Alexander-Scott, N., 2017b. Development and dissemination of a statewide, publicly accessible drug overdose surveillance and information system. Am. J. Public Health in press.

Merrall, E.L., Kariminia, A., Binswanger, I.A., Hobbs, M.S., Farrell, M., Marsden, J., Hutchinson, S.J., Bird, S.M., 2010. Meta-analysis of drug-related deaths soon after release from prison. Addiction 105, 1545-1554.

Montanaro, M., Alexander-Scott, N., Green, T.C., Rich, J.D., Marshall, B.D., Bratbertg, J., Goyer, J., McCance-Katz, E., Macmadu, A., Kinnard, E., Brinkley-Rubinstein, L., 2015. Rhode Island's Strategic Plan on Addiction and Overdose: Four Strategies to Alter the Course of an Epidemic. Rhode Island Department of Health (RIDOH) and Department of Behavioral Healthcare Developmental Disabilities and Hospitals (BHDDH).

Mumola, C.J., Karberg, J.C., 2006. Bureau of Justice Statistics Special Report: Drug Use and Dependence, State and Federal Prisoners, 2004. U.S. Department of Justice, Office of Justice Programs.

O'Donnell, J.K., Gladden, R.M., Seth, P., 2017. Trends in deaths involving heroin and synthetic opioids excluding methadone, and law enforcement drug product reports, by census region-United States, 2006-2015. MMWR Morb. Mortal. Wkly. Rep. 66, 897-903.

Rhode Island Department of Corrections, 2015. Fiscal Year 2015 Annual Population Report. . Accessed at: http://www.doc.ri.gov/administration/planning/docs/FY15\%20Population $\% 20$ Report.pdf.

Rhode Island Department of Health, 2016. Drug Overdose Deaths. Accessed at: http://www. health.ri.gov/data/drugoverdoses.

Rudd, R.A., 2016. Increases in drug and opioid-involved overdose deaths-United States: 2010-2015. MMWR Morb. Mortal. Wkly. Rep. 65, 1445-1452.

Spaulding, A.C., Seals, R.M., McCallum, V.A., Perez, S.D., Brzozowski, A.K., Steenland, N.K., 2011. Prisoner survival inside and outside of the institution: implications for health-care planning. Am. J. Epidemiol. 173, 479-487.

U.S. Department of Health and Human Services, 2014. National Survey on Drug Use and Health: Comparison of 2011-2012 and 2012-2013 Model-Based Prevalence Estimates (50 States and the District of Columbia). Substance Abuse and Mental Health Services Administration. U.S. Department of Health and Human Services.

Warner, M., Chen, L.H., Makuc, D.M., 2009. Increase in fatal poisonings involving opioid analgesics in the United States, 1999-2006. NCHS Data Brief 22, 1-8.

Zlodre, J., Fazel, S., 2012. All-cause and external mortality in released prisoners: systematic review and meta-analysis. Am. J. Public Health 102, e67-e75. 